\title{
Padrões de atividade locomotora diária de Bothrops jararacussu (Serpentes: Viperidae): Uma resposta relacionada às condições ambientais de luminosidade ou a ritmos endógenos?
}

\author{
José Geraldo Pereira da Cruz* \\ Débora Delwing Del Magro \\ Júlia Niehues da Cruz \\ Universidade Regional de Blumenau \\ Centro de Ciências Exatas e Naturais - Departamento de Ciências Naturais \\ Rua Antônio da Veiga, 140 \\ CEP 89010-971 - Blumenau - Santa Catarina \\ *Autor para correspondência \\ jgcruz@furb.br
}

Submetido em 08/05/2008

Aceito para publicação em 26/08/2008

\section{Resumo}

Embora a maioria dos biologistas circadianos provavelmente assuma que os relógios circadianos controlem os padrões de atividade, também é sabido que estímulos ambientais podem mascarar os ritmos endógenos, quer pelo aumento ou pela supressão da atividade. A hipótese de que ritmos circadianos são geralmente controlados pelos ciclos exógenos, foi testada experimentalmente em Bothrops jararacussu. Neste estudo, investigamos a atividade locomotora sobre condições de luminosidade e escuro constantes durante 24 dias e comparamos com os controles, submetidos ao um ciclo de claro/escuro. Sob um ciclo claro/escuro foi observado um pico de atividade durante a fase noturna do ciclo, ritmo circadiano típico de espécies noturnas. Em condições constantes de luminosidade, espécimes de Bothrops jararacussu exibiram significativa fragmentação com aumento global na atividade locomotora e, em escuro constante, significativa supressão da atividade. Provavelmente, o ritmo circadiano é endógeno, primariamente sincronizado pela alternância de claro e escuro. Luminosidade constante induz desincronização e escuro constante bloqueio dos relógios circadianos. O significado funcional destas alterações circadianas sugere pequena flexibilidade na organização circadiana em resposta às condições do ambiente.

Unitermos: atividade locomotora, Bothrops, fotoperíodo, ritmo circadiano, serpentes

\section{Abstract}

Daily patterns of the locomotor activity of Bothrops jararacussu (Serpentes: Viperidae): A response to environmental lighting conditions or an endogenous rhythm? While most circadian biologists would probably assume that circadian clocks drive activity patterns, it is also well known that environmental stimuli may mask endogenous rhythms by either increasing or suppressing activity. The hypothesis that circadian rhythms are generally entrained by exogenous cycles was experimentally tested in Bothrops jararacussu. In this study, we investigated the locomotor activity under constant light and constant dark conditions for 24 days and compared it to that of control snakes living under a light/dark cycle. Under the light/dark cycle, one 
peak of activity was observed during the night phase, which is typical of the circadian rhythms of nocturnal species. Constant light on Bothrops jararacussu promoted a significant fragmentation and an overall increase in the amount of locomotor activity, while constant darkness provoked a significant suppression of activity. This circadian rhythm is probably endogenous, primarily synchronized by alternating light and darkness. Constant light induces desynchronization, and constant darkness leads to the blockage of circadian clocks. The functional significance of these circadian changes suggests a small flexibility in circadian organization in response to environmental conditions.

Key words: Bothrops, circadian rhythm, locomotor activity, photoperiod, snakes

\section{Introdução}

Muitos parâmetros comportamentais e fisiológicos mostram variações que persistem quando as condições ambientais permanecem constantes, como as de laboratório. Os ritmos que persistem em condições constantes, com períodos próximos de 24h, são chamados circadianos (Murphy e Campbell, 1996).

Baseado no grau de atividade, as serpentes podem ser classificadas em diurnas, noturnas ou crepusculares. O período de atividade induz profundas alterações comportamentais, sendo ecologicamente importante nos ciclos diários. Bothrops jararacussu é uma espécie estritamente noturna, com ritmos de atividade locomotora fortemente sincronizada pela luz (Pereirada-Cruz, 2006). Estas características comportamentais da $B$. jararacussu obtidas em laboratório podem ser comparadas com outras espécies deste gênero obtidas na natureza, como B. moojeni (Leloup, 1984), B. jararaca (Sazima e Manzaini, 1995) e B. neuwiedi (Borges e Araújo, 1998). Acredita-se que o sistema circadiano tenha evoluído no sentido de melhor preparar o organismo para enfrentar as mudanças do ambiente associadas ao ciclo claro/escuro como alimentação, reprodução e hibernação (Jayne e Bennett, 1990; Goldman, 1999; Paranjpe e Sharma, 2005).

Daan et al. (2001) sugeriram a presença de dois osciladores genéticos, ativados pelo grau de radiação de luminosidade produzida pela estação do ano, sendo que a intensidade da luminosidade poderia ser avaliada pelo sistema nervoso central e atuar sobre dois pares de genes circadianos (per1, cry1, per2 e cry2). O oscilador per1/ cry1 seria acelerado pela luz e desacelerado pelo escuro; enquanto o oscilador per2/cry2 seria desacelerado pela luz e acelerado pelo escuro, fornecendo um perfeito mecanismo molecular para mensurar as estações do ano e a intensidade da atividade locomotora. Em $B$. jararacussu, provavelmente, existam dois ou mais relógios envolvidos na regulação dos ritmos locomotores circadianos. Estes relógios devem ser mutuamente complementares, modulando informações temporais ao longo do sistema nervoso central, com livre-curso ao longo de um período de $24 \mathrm{~h}$, em ciclo de claro/escuro (Pereira-da-Cruz, 2007). A comparação de homólogos do gene per2 em répteis, aves e mamíferos demonstrou uma mesma seqüência gênica, sendo sua transcrição influenciada pelo mesmo grau de luminosidade e temperatura (Albrecht et al., 1997; Brandstätter et al., 2001; Magnone et al., 2005).

Nas condições naturais, devemos considerar que outros fatores abióticos, como a temperatura e a umidade, influenciam o comportamento. Dados relacionados à soltura e recaptura indicam que a $B$. moojeni utiliza áreas pequenas por longos períodos, causada pela baixa mobilidade da espécie, sendo mais ativa durante os meses de verão, quando ocorre alta intensidade de radiação solar, temperatura e umidade relativa do ar (Oliveira e Martins, 2002).

Atividades locomotoras controladas por ritmos circadianos são descritas em muitas espécies de répteis (Underwood, 1990). A maioria dos estudos investiga o ritmo de atividade locomotora para determinar como o grau de ritmicidade circadiana manifesta-se através da variação do fotoperíodo. Isto permite definir o sincronismo interno em relação às condições do ambiente. Estudos de atividade locomotora de B. jararacussu realizados em laboratório, sugere que a luz é um potente fornecedor de tempo para esta espécie, a exemplo do que ocorre na maioria dos animais, demonstrando que estes são capazes de modificar seu ritmo de atividade de acordo com as variações de luminosidade presente no ambiente. A inversão do ciclo natural de luminosidade 
é capaz de bloquear a atividade, possivelmente através da modulação de osciladores circadianos responsáveis pelo controle da atividade locomotora (Pereira-daCruz, 2007). Entretanto, os mecanismos moleculares pelos quais estas manifestações comportamentais se manifestam, através destes relógios biológicos, ainda não foram descritos. Acredita-se que existe um limite neste ciclo para que a singularidade comportamental se manifeste através da ação dos estímulos exógenos sobre o relógio biológico, na presença de osciladores circadianos dentro deste ciclo/limite.

Fica evidente que os mecanismos fotoreceptivos são utilizados regularmente pelos relógios biológicos, mas o entendimento de como o sistema sensorial detecta a luz e controla os ritmos circadianos em serpentes, ainda não é esclarecido. A jararacuçu (B. jararacussu Lacerda, 1884) apresenta especial interesse para o estudo do sistema circadiano de ofídios, devido à sua grande distribuição geográfica. Assim, no presente estudo, procurou-se monitorar a atividade locomotora em $B$. jararacussu durante 24 dias sob luminosidade e escuro constante, objetivando o entendimento da organização circadiana e a influência da luz sobre este sistema.

\section{Material e Métodos}

Os experimentos foram realizados com dez serpentes mantidas em condições de ciclo claro/escuro ambiental 12:12, no período compreendido entre 21 de setembro a 21 de dezembro de 2006, na primavera. Foram estudadas B. jararacussu de 18 meses de idade, pesando em média $49,1 \pm 2,7 \mathrm{~g}$ e comprimento médio de 48,0 $\pm 2,6 \mathrm{~cm}$; obtidas no serpentário da Universidade Regional de Blumenau, no Estado de Santa Catarina, Brasil (Certificado de Registro de Criadouro da Fauna Silvestre - 900238/IBAMA).

Dez jovens animais mantidos durante 24 dias no serpentário em ciclo claro/escuro ambiental 12:12 (dia/claro e noite/escuro), tiveram sua atividade locomotora avaliada após este período de aclimatação, sendo utilizados como referência para os testes comportamentais. Posteriormente, estes mesmos animais foram divididos em dois grupos de cinco animais, sendo submetidos durante 24 dias às seguintes condições: o primeiro grupo, à luminosidade constante (claro/claro), e o segundo grupo, a escuro constante (escuro/escuro), tendo sua atividade locomotora avaliada a cada seis dias.

A avaliação da atividade locomotora foi filmada no laboratório do serpentário na cidade de Blumenau no estado de Santa Catarina, com temperatura ambiente de $24 \pm 1{ }^{\circ} \mathrm{C}$ e umidade relativa do ar de $56 \pm 2 \%$, utilizando-se uma arena de madeira (Figura 1). O interior desta arena, de $280 \mathrm{~cm}$ de diâmetro e $50 \mathrm{~cm}$ de altura, foi pintado de preto e o assoalho foi subdividido em segmentos de linhas brancas para formar 19 espaços iguais $(15 \mathrm{~cm}=$ distância total para cada espaço $)$.

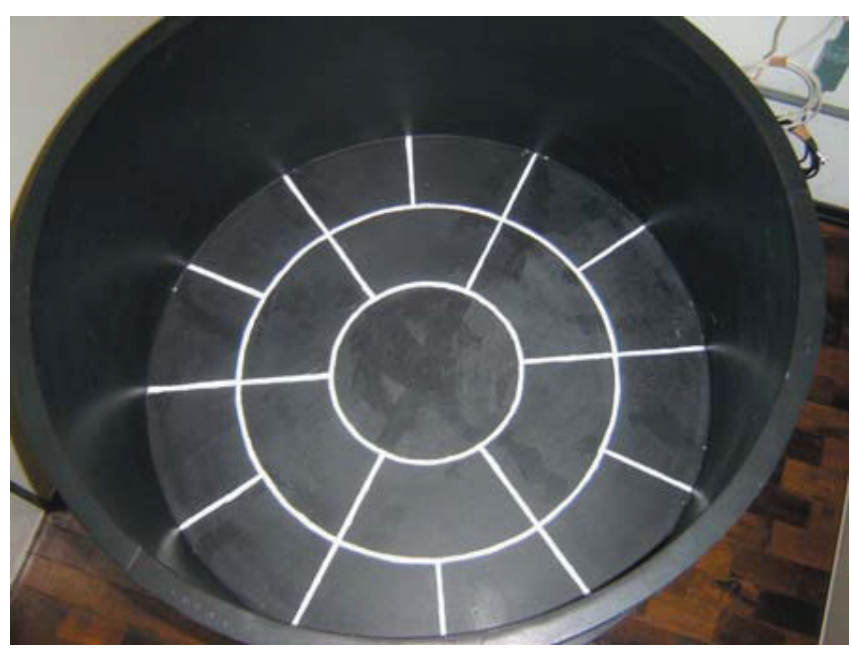

FIGURA 1: Arena de madeira limitada por uma parede circular.

A ambulação foi aferida a partir da anotação do número de setores desenhados no chão do aparelho que foram transpassados pelo animal pela distância de cada espaço, com os dados coletados em intervalos de $2 \mathrm{~h}$ de forma não acumulativa, durante um período de $24 \mathrm{~h}$.

Os dados coletados foram utilizados para análise de variância. Após ser observada a significância do teste $\mathrm{F}$ da análise de variância menor que $5 \%(\mathrm{p}<0,05)$, utilizou-se o teste de Tukey para comparação das médias tomadas duas a duas.

\section{Resultados}

A atividade locomotora mais intensa para os animais mantidos em ciclo claro/escuro no final de um período de 24 dias ocorreu entre 16:00 e 24:00h, com 
picos máximos entre 18:00 e 20:00h $(13,7 \pm 1,0$ e 13,2 \pm $0,4 \mathrm{~m}$, respectivamente). A análise de variância apresentou significância $(F=42,661 ; p<0,001 ; N=5)$; com o teste de Tukey mostrando diferenças significativas para os períodos compreendidos entre 02:00 e 14:00h, quando comparados a outros períodos $(p<0,05)$ (Figura 2).

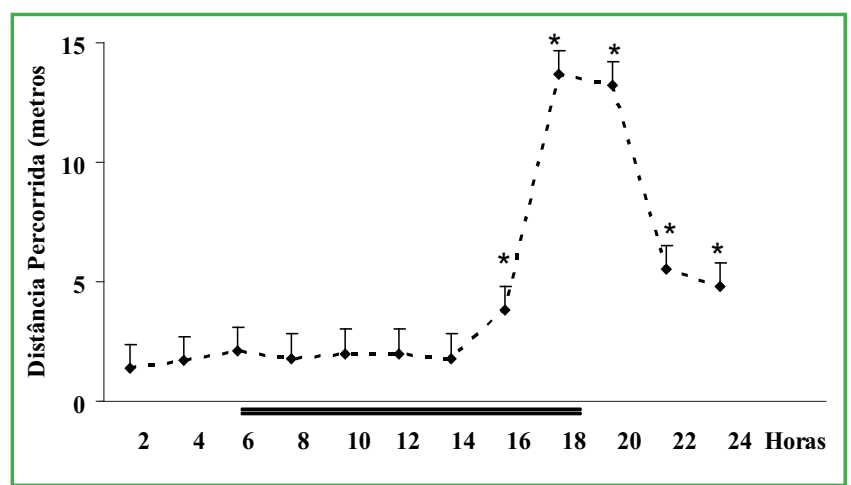

FIGURA 2: Variações na atividade locomotora durante período de $24 \mathrm{~h}$ de $B$. jararacussu após serem submetidas aos ciclos de claro/escuro durante 24 dias. A barra no eixo das horas representa o período normal de dia/claro e as linhas verticais acima dos pontos representam o erro padrão da média. O teste de Tukey mostrou diferenças significativas na distância percorrida entre 02:00 e 14:00h quando comparada com o período entre 16:00 e 24:00h $(n=5 ; * p<0,05)$.
Bothrops jararacussu mostrou oscilações na atividade locomotora quando mantida em luminosidade constante, com analise de variância mostrando diferenças significativas entre as médias nos períodos de $24 \mathrm{~h}$, mas sem apresentar um padrão de ritmicidade $(\mathrm{F}=29,668$, $\mathrm{p}<0,001 ; \mathrm{N}=5$ ). Diferenças na locomoção foram observadas a partir do sexto dia nos animais submetidos ao protocolo claro/claro (Figura 3).

Análise de variância mostrou diferenças significativas na atividade locomotora após o $6^{\circ}$ dia nos animais submetidos a escuro constante, quando comparado com o dia zero do experimento $(\mathrm{F}=78,192$; $\mathrm{p}<0,001 ; \mathrm{N}=5$ ), com o teste de Tukey mostrando um bloqueio desta atividade (Figura 4).

Apesar da baixa atividade locomotora em $B$. jararacussu submetida à condição experimental escuro/escuro, estas respondiam à presença de alimento no ambiente, movimentando-se em direção à presa, realizando o bote e ingestão (dados não demonstrados).

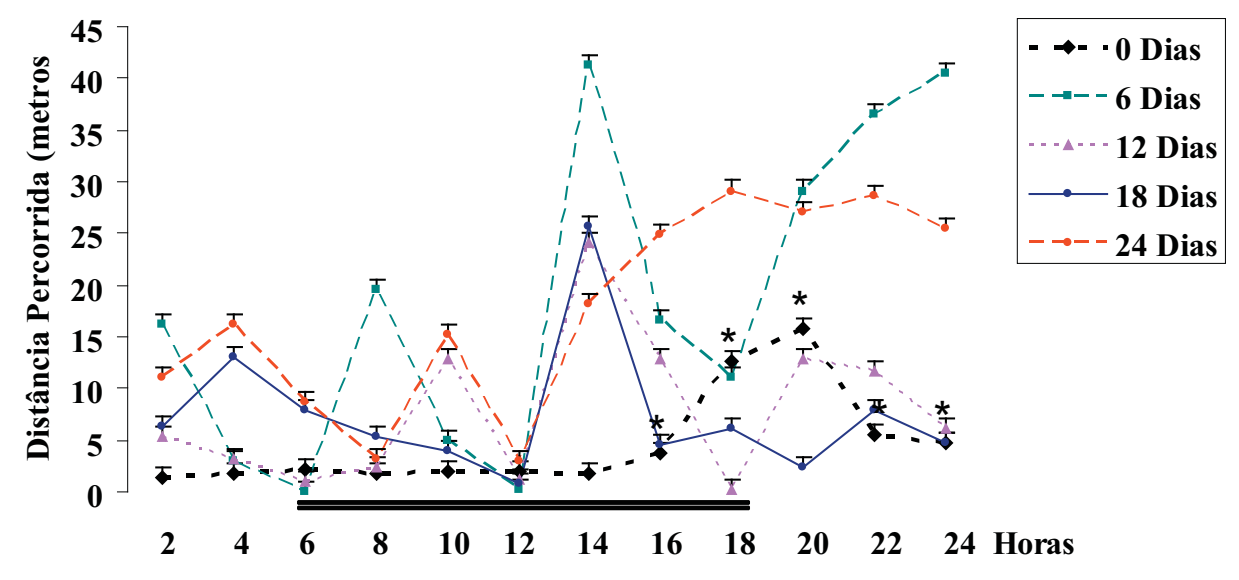

FIGURA 3: Variações na atividade locomotora durante períodos de 24h de B. jararacussu submetidas a um período de luminosidade constante durante 24 dias. A barra no eixo das horas representa o período normal de dia/claro e as linhas verticais acima dos pontos representam o erro padrão da média. O teste de Tukey mostrou diferenças significativas nas médias das distâncias percorridas em diferentes situações, não havendo um padrão de ritmicidade nas observações realizadas a partir do sexto dia, como observado no dia zero do experimento $(\mathrm{n}=5 ; * \mathrm{p}<0,05)$. 


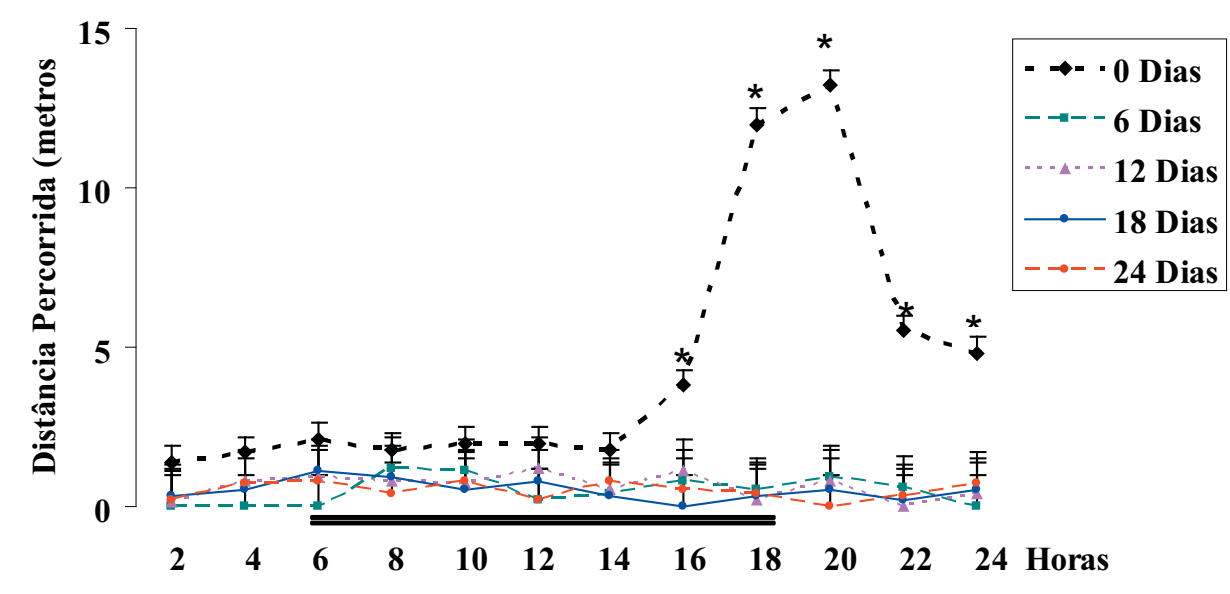

FIGURA 4: Variações na atividade locomotora durante períodos de $24 \mathrm{~h}$ de $B$. jararacussu submetidas a um período de escuro constante durante 24 dias. A barra no eixo das horas representa o período normal de dia/claro e as linhas verticais acima dos pontos representam o erro padrão da média. Análise de variância não mostrou diferenças significativas na atividade locomotora a partir do sexto dia quando os animais apresentaram um bloqueio na atividade, quando comparados com o dia zero do experimento $(\mathrm{n}=5 ; * \mathrm{p}<0,05)$.

\section{Discussão}

Quase todas as espécies de animais apresentam comportamentos adaptados a um ciclo diário de $24 \mathrm{~h}$, com seu zeitgeber influenciado pela luz. Animais com hábitos noturnos, diurnos ou crepusculares são capazes de sincronizar seus ritmos biológicos com as mudanças de luminosidade (Redlin et al., 2003). O estudo da atividade locomotora da $B$. jararacussu realizado em cativeiro, sugere que a luz é um potente zeitgeber para estes animais (Pereira-da-Cruz, 2007). Nas condições de ciclo claro/escuro, B. jararacussu apresentou hábito noturno, com maior período de atividade locomotora entre 16 e $24 \mathrm{~h}$, com dias e noites subjetivas geradas artificialmente no laboratório (Figura 1). Estas características comportamentais da $B$. jararacussu obtidas em laboratório podem ser comparadas com outras espécies deste gênero obtidas na natureza, como B. moojeni (Leloup, 1984), B. jararaca (Sazima e Manzaini, 1995) e B. neuwiedi (Borges e Araújo, 1998).

Estas observações comportamentais demonstram que $B$. jararacussu é capaz de distinguir variações de luminosidade e modificar seu ritmo de atividade locomotora de acordo com o regime de claro/escuro presente no ambiente. A endogenicidade destes ritmos proporciona uma capacidade antecipatória que permite a estes animais organizar recursos fisiológicos e comportamentais, fornecendo uma resposta mais eficiente às alterações do ambiente para obtenção de alimento ou proteção contra predadores em ciclo claro/ escuro (Shine e Lambeck, 1990; Paranjpe e Sharma, 2005).

A luminosidade é um dos fatores primordiais dos eventos sazonais, apesar de outros fatores como umidade e temperatura também podem influenciar o sistema circadiano. A hora do dia em que os animais termodependentes são ativos apresenta conseqüências importantes. Os parâmetros fisiológicos como atividade enzimática, funções imunológicas, termogênese, armazenamento ou mobilização das reservas de energia, devem ser bem ajustados às mudanças ambientais. Coerentemente, mudanças comportamentais relacionadas à alimentação, reprodução e hibernação, muitas vezes devem preceder os eventos externos. Várias espécies de serpentes demonstram modificações na atividade locomotora controlada pelo sistema circadiano e são influenciadas pelos ciclos de claro/escuro do ambiente (Norris e Kavanau, 1966; Thomas e Thomas, 1978; Griffiths, 1984). Assim, as comparações interespecíficas 
de animais termodependentes não devem considerar apenas a temperatura em relação à hora do dia que estes animais são mais ativos, mas também o desempenho dos ritmos circadianos em relação a outros fatores abióticos como a luminosidade, intensidade de radiação solar, umidade relativa do solo e/ou do ar (Llewelyn et al., 2006).

Entretanto, a perda de ritmiciadade em $B$. jararacussu submetida à luminosidade constante, sugere uma fraca ligação entre o relógio biológico e uniformidade dos ritmos. A exposição da B. jararacussu a longo período de luminosidade é capaz de desincronizar os osciladores circadianos responsáveis pela modulação da atividade locomotora, ocasionando uma significativa fragmentação, com aumento global na atividade locomotora (Figura 3). Comportamentos singulares como estes foram descritos em algas, insetos, aves e mamíferos (Engelmann et al., 1978; Yoshii et al., 2004; Van Oort et al., 2005; Kumar et al., 2007), podendo estar presente em todos os relógios biológicos.

Um bloqueio na atividade em $B$. jararacussu foi observado quando estes animais foram mantidos em escuro constante (Figura 4), demonstrando a incapacidade do relógio biológico em manter a atividade locomotora. Resultados semelhantes foram obtidos em nosso laboratório quando submetemos $B$. jararacussu a uma inversão no ciclo de luminosidade (Pereira-daCruz, 2007). Nestas duas condições experimentais, a baixa capacidade locomotora é apenas aparente, pois os animais sempre se movimentavam para capturar o alimento. Entretanto, os mecanismos moleculares pelos quais estas manifestações comportamentais se manifestam, através dos relógios biológicos, ainda não foram descritos.

Os resultados obtidos demonstram a forte influência exógena da luminosidade na atividade locomotora de $B$. jararacussu, sendo capaz de afetar todos os animais colocados nas condições experimentais de escuro ou luminosidade constante. Portanto, a luz seria um dos fatores determinantes na sincronização e atividade locomotora em B. jararacussu. Esta característica consiste na sincronização dos ritmos endógenos e exógenos alcançados através de diferentes osciladores internos que respondem às variações rítmicas de luminosidade do ambiente. A forma como estes ritmos são estabelecidos depende do grau de sincronia entre osciladores. Em B. jararacussu, onde a maioria dos indivíduos apresenta ritmos monofásicos quando submetidos a ciclos claro/escuro, possivelmente ocorra devido ao acoplamento dos osciladores endógenos ao fotoperíodo do ambiente, permitindo a contínua geração destes ritmos. Entretanto, são desacoplados quando estes animais são submetidos à luminosidade ou escuro constante. Nas condições de escuro ou luminosidade constantes os osciladores endógenos são aparentemente bloqueados ou desincronizados por influência do ambiente, ocasionando a perda do ritmo de atividade locomotora em B. jararacussu.

Os resultados comportamentais obtidos em laboratório sugerem uma baixa flexibilidade dos osciladores endógenos em repostas às condições do ambiente, demonstrando a importância das pesquisas futuras para o entendimento da expressão destes osciladores endógenos em relação à variação de luminosidade do ambiente.

\section{Referências}

Albrecht, U.; Sun, Z. S.; Eichele, G.; Lee, C. C. 1997. A differential response of two putative mammalian circadian regulators, mper1 and mper2, to light. Cell, 91 (7): 1055-1064.

Borges, R. C.; Araújo, A. F. B. 1998. Seleção de hábitat em duas espécies de jararaca (Bothrops moojeni Hoge e B. neuwiedi Wagler) (Serpentes, Viperidae). Revista Brasileira de Biologia, 58 (4): 591-601.

Brandstätter, R.; Abraham, U.; Albrecht, U. 2001. Initial demonstration of rhythmic Per gene expression in the hypothalamus of a non-mammalian vertebrate, the house sparrow. NeuroReport, 12 (6): 1167-1170.

Daan, S.; Albrecht, U.; Van der Horst, G. T. J.; Illnerova, H.; Roenneberg, T.; Wehr, T. A. 2001. Assembling a clock for all seasons: are there $\mathrm{M}$ and $\mathrm{E}$ oscillators in the genes? Jurnal of Biological Rhythms, 16 (2): 105-116.

Engelmann, W.; Johnsson, A.; Kobler, H.G.; Schimmel, M. 1978. Attenuation of the petal movement rhythm in Kalanchoe with light pulses. Physiologia Plantarum, 43 (1): 68-76.

Goldman, B. D. 1999. The circadian timing system and reproduction in mammals. Steroids, 64 (9): 679-685.

Griffiths, R. A. 1984. The influence of light and temperature on diel activity rhythms in the sand boa, Eryx conicus. Journal of Herpetology, 18 (4): 374-380.

Jayne, B. C.; Bennett, A. F. 1990. Selection on locomotor performance capacity in a natural population of garter snakes. Evolution, 44 (5): 1204-1229. 
Kumar, V.; Van't Hof, T. J.; Gwinner, E. 2007. Circadian behavioral and melatonin rhythms in the European starling under light-dark cycles with steadily changing periods: Evidence for close mutual coupling? Hormones and Behavior, 52 (4): 409-416.

Leloup, P. 1984. Various aspects of venomous snake breeding on a large scale. Acta Zoologica et Pathologica Antverpiensia, 78 (1): 177-198.

Llewelyn, J.; Shineand, R.; Webb, J. K. 2006. Time of testing affects locomotor performance in nocturnal versus diurnal snakes. Journal of Thermal Biology, 31 (3): 268-273.

Magnone, M. C.; Jacobmeier, B.; Bertolucci, C.; Foà, A.; Albrecht, U. 2005. Circadian expression of the clock gene Per2 is altered in the ruin lizard (Podarcis sicula) when temperature changes. Molecular Brain Research, 133 (2): 281-285.

Murphy, P. J.; Campbell, S. S. 1996. Physiology of the circadian system in animals and humans. Journal of Clinical Neurophysiology, 13 (1): 2-16.

Norris, K. S.; Kavanau, J. L. 1966. The burrowing of the Western Shovel-nosed snake, Chionactis occipitalis, and the undersand environment. Copeia, 4 (1): 650-664.

Oliveira, M. E.; Martins, M. 2002. When and where to find a pitviper: Activity patterns and habitat use of the lancehead, Bothrops atrox, in central Amazonia, Brazil. Herpetological Natural History, 8 (2): 101-110.

Paranjpe, D. A.; Sharma, V. K. 2005. Evolution of temporal order in living organisms. Journal of Circadian Rhythms, 3 (1): 1-13.

Pereira-da-Cruz, J. G. 2006. Performance locomotora entre Bothrops jararacussu (Serpentes, Viperidae) versus Spilotes pullatus (Serpentes, Colubridae). Biociências, 14 (2): 202-207.
Pereira-da-Cruz, J. G. 2007. Ritmo circadiano e atividade locomotora em Bothrops jararacussu (Serpentes, Viperidae). Biotemas, 20 (3): 55-61.

Redlin, U.; Cooper, H. M.; Mrosovsky, N. 2003. Increased masking response to light after ablation of the visual cortex in mice. Brain Reseach, 965 (1-2): 1-8.

Sazima, I.; Manzani, P. R. 1995. As cobras que vivem numa reserva florestal urbana. In: Morellato, L. P. C. \& Leitão-Filho, H. F. (Eds). Ecologia e preservação de uma floresta tropical urbana: Reserva de Santa Genebra. Ed. Unicamp, Campinas, Brasil, p.8-82.

Shine, R.; Lambeck R. 1990. Seasonal shifts in the thermoregulatory behaviour of Australian blacksnakes Pseudechis porphyriacus. Journal of Thermal Biology, 15 (1): 301-305.

Thomas, K. R.; Thomas, R. 1978. Locomotor activity responses to photoperiod in four west Indian fossorial squamates of the genera Amphisbaena and Typhlops (Reptilia, Lacertilia). Journal of Herpetology, 12 (1): 35-41.

Underwood, H. 1990. The pineal and melatonin: Regulators of circadian function in lower vertebrates. Experientia, 46 (1): 120128.

Van Oort, B. E. H.; Tylert, N. J. C.; Gerkema, M. P.; Folkow, L.; Blix, A. S.; Stokkan, K. A. 2005. Circadian organization in reindeer. Nature, 438 (22): 1095-1096.

Yoshii, T.; Funada, Y.; Ibuki-Ishibashi, T.; Akira Matsumoto, A.; Tanimura, T.; Tomioka, K. 2004. Drosophila $c r y^{b}$ mutation reveals two circadian clocks that drive locomotor rhythm and have different responsiveness to light. Journal of Insect Physiology, 50 (6): 479-488. 